\title{
RESPETO Y RETRIBUCIÓN: LA PENA JURÍDICA \\ EN LA METAFÍSICA DE LAS COSTUMBRES*
}

\author{
Respect and Retribution: Legal Punishment \\ in The Metaphysics of Morals
}

\section{JUAN PABLO MAÑALICH}

\author{
Universidad de Chile
}

\begin{abstract}
RESUMEN
El artículo ofrece una lectura de la sección de la Metaphysik der Sitten en la cual Kant perfila una concepción secular de la pena jurídica, anclada en la postulación de un (meta-)principio del respeto como premisa normativa. Sobre esta base, se indaga en la significación precisa de la caracterización de la ley penal como un "imperativo categórico", así como en el estatus del "derecho de retribución" como parámetro de conmensuración de la pena. Por esta vía se intenta desvirtuar tanto la asociación de la concepción de Kant con el leitmotiv de una realización metafísica de la justicia, como su reinterpretación como una variante de teoría mixta, que combinaría una finalidad de prevención con un mero constreñimiento de proporcionalidad por merecimiento.
\end{abstract}

Palabras clave: Kant, retribución, principio del respeto, ius talionis, merecimiento

\begin{abstract}
The paper offers a reading of the section of the The Metaphysics of Morals in which Kant advances a secular conception of the legitimation of legal punishment, based upon the postulation of a (meta-)principle of respect as normative premise. On this basis, the precise meaning of the characterization of penal law as a "categorical imperative" is addressed, as well as the status of the "right of retribution" as standard for the commensuration of punishment. In this way, the paper seeks to undermine the linkage of Kant's conception with the leitmotiv of a metaphysical realization of justice, as well as its interpretation as a version of a mixed theory, which would allegedly combine a deterrence goal with a mere side-constraint of desert-based proportionality.
\end{abstract}

Keywords: Kant, retribution, respect principle, ius talionis, desert

\footnotetext{
Una versión preliminar de este trabajo fue presentada como ponencia en el taller La filosofía política y jurídica de Kant, celebrado en la Pontificia Universidad Católica de Valparaíso, el 31 de julio de 2017, por cuya organización agradezco a Enzo Solari; una versión posterior fue presentada y discutida en el marco de las Jornadas Chilenas de Filosofía Jurídica y Social, celebradas en Valparaíso los días 2 y 3 de noviembre de 2017. Agradezco a las y los participantes en ambos foros por las observaciones recibidas, así como a Felipe Bonzi, ayudante ad honorem del Departamento de Ciencias Penales de la Facultad de Derecho de la Universidad de Chile, por su generosa ayuda editorial. Quisiera dedicar este artículo a honrar la memoria de Joachim Hruschka, quien falleciera el 10 de diciembre de 2017, sin el conocimiento de cuya vasta y monumental obra intelectual, también en lo tocante a la exégesis de Kant, mis propios esfuerzos de teorización del derecho penal serían apenas concebibles.
} 


\section{LA PERPLEJIDAD EXEGÉTICA}

En 1968, el jurista alemán Ulrich Klug ofrecía una no muy cordial "despedida" a Kant y Hegel del foro de la teoría de la justificación de la pena, bajo el predicamento de que las teorías retribucionistas, en lo fundamental determinadas por los "sistemas filosóficos" de ambos titanes del idealismo alemán, fracasarían manifiestamente al ser medidas bajo los estándares de legitimación secular propios de un Estado de derecho (Klug 1981: 149 y ss.). ${ }^{1}$

En el ínterin, empero, han surgido propuestas de refutación -algunas de ellas marcadamente enérgicas - de esa misma despedida. Lapidario, al respecto, resulta ser el veredicto de Hruschka:

El arrogante proceder de Klug con los textos de Kant ha conducido a un panfleto que se queda muy por debajo de los requerimientos mínimos que han de ser puestos a un trabajo científico (Hruschka 2010: 503).

La eficacia del proceder Klug contribuye a explicar, con todo, que las persistentes referencias que siguen siendo hechas a Kant, en los debates de la filosofía jurídico-penal, muchas veces se contenten con reducir su contribución a la de haber formulado una objeción - la así llamada "objeción kantiana" - a las teorías de la prevención, según la cual una punición no fundamentada en el hecho de que el condenado ha delinquido, sino impuesta "meramente como un medio para promover algún otro bien, sea para el criminal mismo o para la sociedad civil", sitúa a aquel "entre los objetos del derecho de las cosas" (Kant 1798: A 196, B 226). ${ }^{2}$

Más allá de la celebración de este drástico llamado de atención acerca de la instrumentalización de la persona del condenado que es ínsita al pensamiento de la prevención (Wood 2008: 222 y s.; 2010: 126 y ss.), es llamativo cuán dispares llegan a ser las propuestas de exégesis de la correspondiente sección de la Rechtslehre. Ellas oscilan entre una lectura que identifica el así llamado "retribucionismo metafísico" de Kant con una teoría "absoluta" según la cual el sentido de la pena se encontraría "fuera de la realidad social", consistiendo en la satisfacción de una exigencia incondicionada — y en tal medida "categórica"— de justicia, por un lado, ${ }^{3}$ y otra que lo sitúa como un precursor de una teoría mixta o combinatoria, de carácter propiamente consecuencialista, según la cual la legislación penal perseguiría una finalidad de disuasión generalizada de la perpetración de delitos, en tanto que el "principio de retribución" operaría como un criterio de distribución (por merecimiento) y determinación (por proporcionalidad) de la pena susceptible de ser judicialmente impuesta sobre

\footnotetext{
Al respecto véase también Nino (2008: 42 y ss.), así como Hoerster (2012: 25 y ss., 47 y ss.).

Véase al respecto Nino (2008: 43 y ss.), destacando los problemas que han de enfrentar los partidarios de una concepción prevencionista de la pena una vez que se han despedido, con Klug, de Kant y Hegel.

Véase por ejemplo Neumann y Schroth (1980: 11 y ss.); Corlett (2013: 63 y ss.); enfáticamente Hoerster (2012: 29 y ss.); Vilajosana (2015: 26 y ss.). A favor de la clasificación de la concepción kantiana de la pena entre las variantes de "retribucionismo tradicional", véase Donoso (2014: 5242 y ss.).
} 
una persona, por otro (Byrd 1989: 180 y ss.; Byrd y Hruschka 2010: 261 y ss.; Hruschka 2010; 2011; Blöser 2014: 160 y ss.).

Especialmente ilustrativo de esta incertidumbre interpretativa resulta ser el giro experimentado por Jeffrie Murphy. En un primer momento, este creía posible reconstruir, a partir de la sección pertinente, una "teoría fuertemente retributiva del castigo", cuya base estaría dada por una concepción de la obligación política como anclada a un principio de reciprocidad, bajo la cual el comportamiento del criminal quedaría caracterizado como consistente en la obtención de una ventaja injusta, frente a cuya remoción coercitiva aquel no podría esgrimir reclamo alguno, al haber racionalmente consentido su propio castigo (Murphy 1970: 142 y s.; 1979: 82 y ss.). Pero en algo más que tres lustros, su impresión había llegado a ser, más bien, que no parecería posible predicar de Kant haber legado algo "que merezca ser llamado una teoría del castigo en absoluto", sino a lo sumo "un conjunto aleatorio (y no enteramente consistente) de observaciones —algunas de ellas ciertamente sugerentes- acerca del castigo" (Murphy 1987: 509).

El giro de Murphy resulta tanto más notable si se repara en que semejante relectura se nutría de un conjunto de pasajes extraídos de múltiples escritos de Kant, distintos de la Rechtslehre, los cuales arrojarían que, en contraste con la concepción presentada en esta última, Kant habría estado más bien inclinado a favorecer una identificación de la disuasión como objetivo general de la punición, cuya realización, empero, quedaría subordinada a constreñimientos de tinte retributivo, consistentes en la exigencia de culpabilidad como condición necesaria de la imposición particular de una pena y en una exigencia de proporcionalidad como estándar para su conmensuración. Lo llamativo de esto es que Byrd y Hruschka, que han marcado decisivamente el debate más reciente por la vía de atribuir semejante variante de teoría mixta a Kant, lo han hecho interpretando precisamente los célebres pasajes de la Rechtslehre en los cuales Murphy seguía encontrando una forma de "retribucionismo moral" cuya incompatibilidad con aquella variante de teoría mixta volvería irresoluble la duda de si Kant en efecto llegó a abrazar una concepción consistente del sentido y la finalidad de la pena (Murphy 1987: 512 y ss., 518). Y la perplejidad oólo puede aumentar si esto último se contrasta con que un tan reputado exégeta de Kant, como lo es Allen Wood, sostenga que la variante de retribucionismo moral inequívoca e indudablemente defendida por Kant no encontraría anclaje alguno en los fundamentos de su propia filosofía moral y jurídica, la cual sería mucho fácil de reconciliar con una variante de teoría mixta como la que le atribuyen Byrd y Hruschka, que no se dejaría acomodar, sin embargo, con lo efectivamente dicho por Kant (Wood 2008: 213 y ss., 220 y ss.; 2010: 113 y s., 120 y ss.). 


\section{LA LEY PENAL COMO IMPERATIVO CATEGÓRICO}

Probablemente no haya mayor tergiversación de lo efectivamente dicho por Kant en la Metaphysik der Sitten en referencia a la pena jurídica que la que le atribuye haber conceptuado la punición como un "imperativo categórico" (Murphy 1987: 521). Lo que allí se dice, empero, es que "la ley penal es un imperativo categórico" (Kant 1798: A 196, B 226). Tomando al pie de la letra la definición de "imperativo categórico" que es posible extraer del glosario introductorio que Kant ofrece en la forma de una Philosophia Practica Universalis, esto quiere decir que las normas de sanción penal legislativamente establecidas, que correlacionan la realización (imputable) de una determinada forma de comportamiento con la imposición de una determinada consecuencia jurídica de carácter punitivo, tienen el carácter de reglas prácticas que "conciben como objetivamente necesaria y hacen necesaria" la acción consistente en la imposición de la pena así especificada, "no de manera mediata, a través de la representación de algún fin que pudiera ser alcanzado mediante esa acción", sino de manera inmediata, "a través de la sola representación de esta acción misma (de su forma)" (Kant 1798: AB 20). ${ }^{4}$

Esta no es, ciertamente, la única interpretación posible. No es infrecuente que se sostenga que lo único que Kant puede haber querido decir con ello es que la ley penal expresaría una máxima de acción que se deja deducir del ("único") imperativo categórico, según el cual —con arreglo a la primera de sus formulaciones - cada quien ha de actuar de modo tal que la máxima de su voluntad en todo tiempo pueda valer simultáneamente como principio de una legislación general (Zaczyk 1999: 82 y s.). ${ }^{5}$ Esta interpretación se ve desafiada, no obstante, por el hecho de que Kant recurrentemente hable - en pluralde los imperativos categóricos como aquellos imperativos que, en cuanto no condicionados, valen como leyes prácticas (Kant 1788: A 35-37; 1798: AB 1921). ${ }^{6}$ Con ello, es posible asumir que la caracterización de la "ley penal" como un imperativo categórico es ofrecida por Kant al modo de una descripción estructural, en conformidad con la cual la necesidad práctica de imponer la pena en ella prevista, como consecuencia de la realización imputable de la forma de comportamiento instituida como criminal por esa misma ley, no se sujeta a (ulterior) condición alguna. ${ }^{7}$ De esto se sigue, por lo demás, que tampoco tiene sentido alguno sostener, como lo hace Wood (2008: 214; 2010: 112, 118), que Kant postularía una "ley del castigo" consistente en el imperativo categórico de infligir a un criminal un daño equivalente al daño por él delictivamente generado.

\footnotetext{
Al respecto Hruschka (2011: 28 y ss.).

En general, en contra de la derivación de la doctrina del derecho de Kant a partir de su sistema ético construido en torno al imperativo categórico, véase Willaschek (2017: 98 y ss., 114 y ss.).

$\mathrm{Al}$ respecto Birnbacher (2007: 136 y ss.).

Precisamente en este sentido argumenta más recientemente Zaczyk (2008: 250).
} 
Como lo ha notado Hill, para hacer inteligibles las muy apretadas observaciones que Kant ofrece acerca de la fisonomía de la pena jurídica es necesario situarlas en el contexto de un conjunto de "creencias de trasfondo" que Kant probablemente diera por sentadas, en cuanto susceptibles de ser tratadas como "verdaderas $a$ priori" (Hill 1997: 310 y ss.). Entre tales presuposiciones cabe destacar, desde ya, la concerniente al vínculo de imputabilidad que ha de configurarse entre el hecho con significación criminal y la persona sobre la cual la correspondiente pena es impuesta, de manera tal que ese "hecho" (Tat), en cuanto "acción sometida a leyes dotadas de obligatoriedad", "en la medida en que el sujeto es considerado en ella misma según la libertad de su arbitrio" (Kant 1798: AB 22), sea atribuible a esa misma persona, bajo la consideración de esta como su "agente" (Urheber) (Kant 1798: AB 28), como una "contravención" (Übertretung), la cual, en cuanto "hecho contrario a deber" (Kant 1798: AB 23), fundamente la "culpabilidad" (Verschuldung), cuyo "efecto jurídico" es la pena (Kant 1798: AB 28).

Esto último aparece internamente conectado, a su vez, con la caracterización de esa misma "imputación" (Zurechnung), en cuanto capaz de traer consigo las consecuencias jurídicas que se siguen de ese hecho, como una dotada de fuerza jurídica — esto es, como una imputatio judiciaria—, susceptible de ser contrastada con una imputación meramente "enjuiciadora" —esto es, con una imputatio disjudicatoria-, que se reduce al juicio a través del cual una persona es vista como el agente productor de una acción, que entonces, en cuanto susceptible de quedar sometida a leyes dotadas de obligatoriedad, se llama "hecho" (Kant 1798: AB 28). ${ }^{8}$ Esto a su vez supone que la imputación dotada de fuerza jurídica es una para la cual solo se encuentra habilitada una persona física o moral que cuenta, respectivamente, como juez o tribunal (Kant 1798: AB 28). Y esto explica que en la Tugendlehre Kant enfatice la imposibilidad de confundir la pena, en cuanto reacción judicialmente dispuesta al crimen por vía de aplicación de la ley penal, con la venganza, para la cual nadie más que "Dios", en cuanto "supremo legislador moral", se encontraría autorizado (Kant 1798: A 136-137). ${ }^{9}$

La caracterización de cada ley penal como un imperativo categórico, entonces, encuentra su sustento contextual en una comprensión general de la pena jurídica como una institución constitutivamente dependiente de la existencia del derecho público, que instituye a un pueblo como portador de una voluntad colectiva a través de la cual aquel se gobierna a sí mismo (Enderlein 1985: 309 y ss.). Esto ha llevado a Hruschka a sostener que "Kant es el primero que piensa el Estado de Derecho" (Hruschka 2011: 21). El punto tiene importancia para calibrar la precisa función argumentativa que desempeña el experimento mental que Kant construye para ilustrar cuál ha de ser el canon de aplicación de la ley penal en cuanto imperativo categórico.

8 Acerca de la concepción kantiana de la imputación en la literatura más reciente, véase Aichele (2008: 14 y ss.); Byrd y Hruschka (2010: 290 y ss.); Stübinger (2011: 163 y ss.); Sánchez-Ostiz (2008: 53 y ss.). Fundamental al respecto, Blöser (2014: 11 y ss.).

Véase Byrd y Hruschka (2010: 270). 
Célebremente, Kant se imagina una isla habitada por un pueblo que, en cuanto comunidad política, decidiera disolverse, de modo tal que sus integrantes "se esparcieran por la faz de la tierra", para entonces observar que, en tal situación:

antes tendría que ser ejecutado hasta el último asesino ubicado en la cárcel, para que así cada cual experimente de vuelta lo que valen sus hechos, y la deuda de sangre no recaiga sobre el pueblo que no ha exigido esta punición; porque él [el pueblo] puede ser considerado como un participante en esta vulneración pública de la justicia (Kant 1798: A 199, B 229). ${ }^{10}$

Cabe partir notando que Kant aquí está asumiendo que sobre aquel último asesino ubicado en la cárcel ha sido ya judicialmente impuesta, como resultado de la aplicación de la correspondiente ley penal, una pena de muerte, la cual se encuentra pendiente de ejecución (Hruschka 2010: 501). Por otra parte, y frente a la denuncia de un pretendido misticismo implicado en el uso de la expresión "deuda de sangre" (Klug 1981: 153), hay antecedentes lexicográficos que sugieren que, en la época en la que escribía Kant, ella ordinariamente se usaba para designar la situación en que quedaba quien liberaba de la pena de muerte a un criminal que la merecía (Hruschka 2010: 501). Tratándose de una pena ya judicialmente impuesta, no parece haber misticismo alguno en la sugerencia de que contribuir a que aquella no llegue a ser debidamente ejecutada equivaldría a tomar parte en una vulneración pública de la justicia (Wood 2010: 112 y s.).

En tal medida, el carácter categórico de la ley penal en virtud de cuya aplicación la pena es judicialmente impuesta determina que ella tenga que ser necesariamente ejecutada, sin que esta necesidad práctica pueda verse relativizada por consideraciones prudenciales de utilidad (Byrd y Hruschka 2010: 268 y s.). Ello es definitorio del principio de oficialidad al cual, característicamente, un Estado de Derecho somete la persecución, la jurisdicción y la ejecución penal (Hruschka 2010: 501 y s.). Que la comunidad política cuyo derecho público fija las condiciones de validez y corrección de la imposición y ejecución de la pena en cuestión se encuentre ad portas de disolverse a sí misma, deja intacto que la pregunta de si aquella ha de ser impuesta se plantea en una situación en la cual esa misma comunidad política aún subsiste, estando en tal medida sometida a sus propias leyes (Zaczyk 1999: 84 y s.).

\section{EL IUS TALIONIS COMO ESTÁNDAR DE DETERMINACIÓN DE LA PENA}

Probablemente en ningún otro contexto se manifiesta con tanta visibilidad la tendencia a tomar ciertos giros lingüísticos favorecidos por Kant como expresivos de aquello que Wittgenstein caracterizara como un superlativo 
filosófico (Wittgenstein 1958: § 192), que el de su defensa del así llamado "derecho de retribución", que Kant identifica con el ius talionis como parámetro para definir "la especie y el grado" de la pena jurídica, en congruencia con la "justicia pública" (Kant 1798: A 197-199, B 227-229). En contra de la generalizada disposición a identificar esa invocación del ius talionis con la adopción, por parte de Kant, de una concepción estrictamente retribucionista de la pena, una lectura desapasionada del pasaje correspondiente fuertemente sugiere, más bien, que Kant circunscribe esa invocación a la respuesta a la pregunta por la naturaleza y la magnitud de una sanción que, en cuanto legislativamente establecida, pueda llegar a ser judicialmente impuesta como reacción punitiva (Hruschka 2010: 500 y s.: Blöser 2004: 173 y ss.). ${ }^{11}$ En efecto, dice Kant:

Sólo el derecho de retribución (ius talionis), pero, bien entendido, ante los límites del tribunal (no en tu juicio privado), puede indicar determinadamente la cualidad y cantidad de la pena; todos los demás oscilan por allá y por acá, y no pueden contener, en virtud de otras consideraciones capaces de entremezclarse, adecuación con el adagio de la pura y estricta justicia (Kant 1798: A 197-198, B 227-228).

Lo primero que debe observarse aquí es que, así entendido, el "derecho de la retribución" no tiene el estatus de un principio fundamental y autosuficiente, sino el de una directriz que pretende guiar la actividad legislativa y judicial en lo que respecta al establecimiento y la materialización del castigo. Con ello, hay una consideración de practicidad que habla a favor del recurso al ius talionis para asegurar, en la mayor medida posible, la equivalencia sub specie gravedad entre el crimen y la pena, en el sentido de que esa equivalencia sea reconocible ya en atención a la sola configuración fenoménica de la respectiva especie de crimen y la correspondiente clase de pena (Hill 1997: 302, 310). Al mismo tiempo, sin embargo, es igualmente claro que Kant no proclama la validez incondicionada de semejante parámetro de equivalencia, sino que explícitamente reconoce - en un pasaje añadido como suplemento- que hay especies de crímenes respecto de las cuales aquel resulta impracticable, sea porque la imposición de una pena equivalente en el sentido del ius talionis resultaría o bien ontológicamente imposible, como sería el caso tratándose de un condenado por pederastia, o bien moralmente imposible, en cuanto por sí misma constitutiva de "un crimen punible contra la humanidad como tal", como sería el caso tratándose de un condenado por violación (Kant 1798: B 170-171). ${ }^{12}$

La indagación en el fundamento de la restricción del alcance del ius talionis así formulada resulta particularmente importante en lo tocante a las situaciones de imposibilidad moral de imposición de un castigo fenoménicamente equivalente al crimen imputado. Una muy sugerente propuesta interpretativa ha sido

Al respecto también Hill (1997: 301 y ss.); Donoso (2014: 5243).

Si bien Kant no correlaciona separadamente los dos ejemplos mencionados en el texto principal —a los que se añade el bestialismo - con las situaciones de imposibilidad ontológica y de imposibilidad moral, es claro que la correlación sugerida reproduce correctamente la distinción por él introducida. 
desarrollada, a este respecto, por Falls. De acuerdo con esta, la concepción de la pena jurídica delineada por Kant se encuentra determinada por la adopción de un principio de respeto por las personas, que aquí propongo denominar el "(meta-)principio del respeto", ${ }^{13}$ del cual parecería no problemático extraer los siguientes tres subprincipios tradicionalmente entendidos como definitorios de una fundamentación retribucionista de la pena, a saber: (1) el principio de que el castigo sólo está justificado si es merecido, o "principio del merecimiento"; (2) el principio de que el castigo es merecido si y sólo si quien lo padece ha realizado voluntariamente el agravio por el cual está siendo específicamente castigado, o "principio del merecimiento adquirido"; y (3) el principio de que la severidad del castigo merecido es aquella que resulta proporcional a la severidad de ese mismo agravio, o "principio de proporcionalidad" (Falls 1987: 25 y s., 38 y ss.).

Sistemáticamente, el (meta-)principio del respeto se sustenta en el argumento concerniente a la manera en que solo seres racionales, en cuanto capaces de autogobernarse moralmente, pueden reclamar aquella forma de atención o consideración que Kant asocia con la noción de Achtung, que en tal medida resulta definitoria del estatus de persona. ${ }^{14}$ Esto último aparece elucidado, en el contexto de la Grundlegung, en la preparación y explicación de la segunda formulación del imperativo categórico (Kant 1786: AB 66-67), tradicionalmente conocida como la "fórmula de la humanidad". ${ }^{15}$ En el contexto de la Rechtslehre, ello se ve reflejado en aquel pasaje en el cual Kant tematiza la manera en que la punición jurídica priva al condenado de su "personalidad jurídica", dejando intacta, sin embargo, su "personalidad innata" (Kant 1798: A 196, B 226). Aun cuando Falls no la articula explícitamente, no es difícil advertir la conexión que se da entre esta última distinción, por un lado, y la distinción que Falls propone entre las nociones de merecimiento no-adquirido (unearned desert) y merecimiento adquirido (earned desert), por otro (Falls 1987: 39 y s.). La personalidad innata de los animales humanos cuenta, en este sentido, como la base de todo juicio de merecimiento no-adquirido a su respecto; es en este sentido, por ejemplo, que una persona, por el solo hecho de serlo, merece que no se le mienta simplemente por conveniencia de otros, o que no se la mate por diversión (Falls 1987: 39 y s.). El sentido en que el (meta-)principio del respeto lleva a la formulación del principio del merecimiento que informa una concepción retribucionista de la punición, sin embargo, es uno que resulta en que el juicio de merecimiento que condiciona la justificación del castigo ha de ser uno de merecimiento adquirido

13 Su estatus como meta-principio se funda en que se trata de un principio que funciona como la premisa para la formulación de principios, esto es, como un "principio-de-principios".

14 Acerca de la conexión interna que existiría entre la noción de respeto (Achtung) y la noción de persona, véase la pormenorizada nota al pie en la cual Kant define aquella primera noción como "la determinación inmediata de la voluntad a través de la ley y la conciencia de la misma [determinación]", observando que "el objeto del respeto es, por ello, exclusivamente la ley, y más precisamente aquella que nosotros nos imponemos como, empero, necesaria en sí misma", de manera tal que "todo respeto por una persona es, propiamente, respeto por la ley" (Kant 1786: AB 16-17).

15 Acerca del estatus de cada una de las fórmulas alternativas del imperativo categórico ofrecidas por Kant, y de las conexiones existentes entre ellas, véase las diferentes propuestas de reconstrucción ofrecidas por Allison (2011: 176 y ss., 204 y ss., 237 y ss.); Timmermann (2007: 73 y ss., 109 y ss.); y Wood (2008: 66 y ss.). Al respecto, véase también Tugendhat (1993: 131 y ss., 135 y ss.). 
(Falls 1987: 40 y s.). Mas de esto no se sigue, como acertadamente observa Falls, que la noción de merecimiento no-adquirido carezca de relevancia, al mismo tiempo, para la articulación de aquella concepción retribucionista. ${ }^{16}$

En efecto, la noción de merecimiento no-adquirido es irrenunciable para dar cuenta de la manera en que una persona, por el solo hecho de serlo, es alguien que debe ser tratado como un agente autónomo, lo cual supone que aquella llegue a ser responsabilizada por sus acciones. Y si bien hay múltiples esferas en las cuales es pertinente que la cuestión de quién hace, y cómo, responsable a quién quede entregada a la discreción individual, ello estaría fuera de lugar tratándose de la praxis de hacer responsable a personas por realizar formas de comportamiento dotadas de connotación criminal:

If the matter of holding persons accountable for acts prohibited by the core of the criminal law were left in the hands of individuals, then each person would essentially lose the control over her own life that is rightfully hers as an autonomous being. For she would never know what choices would produce what reaction against her, nor would she have any recourse against others beyond her own limited powers and judgments. The use of state legislation rather than individual rule functions to hold persons morally accountable while giving them the maximum possible power of control over their lives (Falls 1987: 41).

De ahí que Falls concluya que las personas, simplemente como personas, merecen que el Estado las haga responsables por la realización de aquellas formas de comportamiento que tienen significación criminal. Y es precisamente en este sentido que cabe entender el célebre dictum de Hegel según el cual el criminal tiene un "derecho a la pena" (Hegel 1821: § 100), en el sentido del principio de justificación subjetiva del castigo (Mañalich 2013a: 169 y ss.). Esto da cuenta de cómo la punición puede convertirse, bajo ciertas condiciones, en la manera en que el Estado hace responsable a una persona por haber delinquido. En los términos de la distinción precedentemente formulada, se trata de que, bajo ciertas condiciones, el Estado hace responsable a una persona por haber perpetrado un crimen, honrando la pretensión sustentada en su merecimiento no-adquirido de ser responsabilizada por sus acciones, por la vía de someterla a un trato congruente con el merecimiento por ella adquirido a través de la perpetración —imputable- del crimen en cuestión. ${ }^{17}$

16 Es importante no confundir la relación que se da entre las nociones de merecimiento no-adquirido y merecimiento adquirido, por un lado, y aquella que se da entre el principio del merecimiento y el principio del merecimiento adquirido, por otro. Pues la noción de merecimiento involucrada en la formulación del principio del merecimiento es una noción no-cualificada, y en tal medida neutral frente a la distinción entre el carácter no-adquirido y el carácter adquirido susceptible de ser exhibido por el merecimiento. Agradezco a Daniela Accatino por haber planteado la pregunta que llevó a identificar la conveniencia de introducir esta última precisión.

17 El trato congruente con el merecimiento adquirido por el criminal ciertamente no necesita consistir, como sin embargo afirma Enderlein (1985: 312 y ss.), en su sometimiento al estatus de cosa. Enderlein funda esta aserción, como pretendido resultado exegético, en un pasaje que integra la "observación general [acerca] de los efectos jurídicos [que se siguen] a partir de la naturaleza de la asociación civil”, con la cual Kant cierra la 
Según Falls, a través de semejante "teoría de la responsabilización moral" es posible dar cuenta, consistentemente, de los tres subprincipios que se siguen del (meta-)principio del respeto, con la salvedad de que ella hace al mismo tiempo reconocible la necesidad de postular un cuarto subprincipio, el así llamado "principio limitativo", que restringe el alcance del principio de proporcionalidad (Falls 1987: 43 y ss.). ${ }^{18}$ Este concierne directamente a la manera en que la correspondiente reacción punitiva resulta merecida, en el sentido de un merecimiento adquirido, en términos de que esa reacción sea congruente, en gravedad, con el crimen cuya perpetración funda el merecimiento de aquella. Pero según ya se anticipara, esto necesita ser puesto en relación con que, genéricamente, el castigo como tal es merecido en el sentido de un merecimiento no-adquirido, en razón de que toda persona, en cuanto tal, merece ser responsabilizada por lo que ella hace. Y esto fija el límite al que queda sometido el principio de proporcionalidad en cuanto estándar para determinar la pena merecida por el criminal: existen formas posibles de tratamiento punitivo que deben ser consideradas per se inmerecidas, en el sentido de un merecimiento no-adquirido, por el hecho de que ellas vuelven imposible que, a través de su padecimiento, el criminal sea hecho responder como un agente moral (Falls 1987: 45 y ss.). Pues si el sentido de la reacción punitiva es expresar desaprobación e intolerancia por el comportamiento criminal imputable a una persona en cuanto agente moral, la materialización de esa reacción en una forma que no honre el trato que esa persona merece, como tal, en cuanto agente moral, constituye una contradicción performativa (Nozick 1981: 374 y ss.).

Como bien advierte Falls, este argumento determina que sean retributivamente problemáticas, y en último término injustificables, algunas formas de castigo que Kant de hecho no tuvo por problemáticas, entre ellas, y destacadamente, la pena de muerte (Mañalich 2007: 174 y ss.). Que Kant no haya sido suficientemente kantiano (Falls 1987: 50 y s.), no es una alegación infrecuente en la literatura que

sección de la Rechtslehre dedicada al "derecho público". En el último de los párrafos que componen aquella observación, Kant sostiene que la única excepción a la proposición según la cual "en el Estado ningún ser humano puede estar desprovisto de toda dignidad, pues él a lo menos tiene la [dignidad] de ciudadano del Estado", corresponde al caso de aquel que "se lleva a sí mismo a ello, a través de su propio crimen", lo cual puede traducirse en que aquel sea conservado con vida, pero transformado en "mero instrumento del arbitrio de otro (sea del Estado, sea de otro ciudadano)", en cuyo caso el primero contará como un "siervo" (Leibeigener) que pertenece en propiedad al segundo, con lo cual este no será, a su respecto, simplemente "señor" (Herr), sino ya "dueño" (Eigentümer), quedando habilitado para hacer uso de él y disponer arbitrariamente de sus fuerzas, "mas no sobre su vida y sus miembros", "como una cosa"; así Kant (1798: A 193-194, B 223224). Enderlein pierde de vista, sin embargo, que el punto así marcado recién aparece en el contraste, que Kant tematiza inmediatamente a continuación, entre la posibilidad de semejante autorreducción delictiva de una persona a la condición de cosa, y la imposibilidad de una correspondiente autorreducción contractual a ese mismo estatus. Pues observa Kant (1798: A 194, B 224): “A través de un contrato nadie puede obligarse a una dependencia tal, mediante lo cual él deje de ser persona; pues sólo como persona puede él celebrar un contrato". De esto no se sigue, empero, que según Kant sea definitorio del concepto de crimen el condicionamiento de semejante transformación del estatus del propio criminal. Pues como Kant mismo sostiene ya en la sección dedicada al "derecho penal" (y al "derecho de gracia"), contra la confusión de su persona "entre los objetos del derecho de las cosas" el criminal está protegido por su personalidad innata (Kant 1798: A 196, B 226), de lo cual se sigue que la privación de su personalidad civil, resultante de la condena que le sea impuesta, precisamente no puede ser identificada con su reducción a la condición de cosa. 
se ocupa de su concepción de la pena. ${ }^{19}$ Pero es difícil poner en cuestión que, por esta vía, la supuesta inconsistencia en la que habría incurrido al desechar la aplicabilidad del ius talionis en aquellas constelaciones que se corresponden con los casos de imposibilidad moral de la imposición de una pena fenoménicamente equivalente, más arriba considerados, deja de ser tal.

\section{EL PRINCIPIO DEL RESPETO CONTRA EL PRINCIPIO DEL CONSENTIMIENTO}

La explicitación del principio del respeto como parámetro general de la justificación del castigo tiene importancia, adicionalmente, para explicar la magnitud de la censura a la que Kant sometiera el célebre argumento abolicionista de la pena de muerte ofrecido por Beccaria (Solari 2008: 23 y s.; Mañalich 2011: 258 y ss.).

El interés de Kant por la propuesta abolicionista de Beccaria se centra exclusivamente en el primero de los dos pasos del argumento elaborado por el segundo, consistente en la negación de que pueda existir tal cosa como un derecho (soberano) a la pena de muerte, y que antecede a su puesta en cuestión de que la pena de muerte pudiera resultar preventivamente indicada. El argumento mediante el cual Beccaria pretendía refutar la existencia de un derecho a la (imposición y ejecución de la) pena de muerte descansa en su invocación de la teoría del contrato social para dar cuenta del "origen de las penas" y el "derecho de castigar". En efecto, el argumento discurre sobre la premisa de que la fundamentación de un derecho a la pena de muerte exigiría asumir que las leyes bajo las cuales pudiera ser impuesta tal pena no son "más que una suma de cortas porciones de libertad de cada uno, que representan la voluntad general como agregado de las [voluntades] particulares" (Beccaria 1764: 74). Esto, porque siendo las leyes nada más que ese agregado de las (mínimas) porciones de libertad cedidas por cada cual, en pos de asegurar el margen de libertad restante, entonces habría que descartar que sean concebibles leyes que contemplasen la pena de muerte dentro del catálogo de penas legalmente establecidas. Pues, se preguntaba Beccaria, “¿[q]uién es aquel que ha querido dejar a los otros hombres el arbitrio de hacerlo morir?" (Beccaria 1764: 74).

Inmediatamente a continuación, Beccaria sugería que, siendola vida "grandísimo entre todos los bienes", no resulta plausible la hipótesis de que la renuncia a la propia vida pudiese quedar comprendida en "el más corto sacrificio de la libertad de cada particular" (Beccaria 1764: 74). Aquí se expresa lo que cabría llamar el "principio del consentimiento" en cuanto criterio de reconocimiento de un derecho punitivo relativo a una forma de pena específica: bajo una hipótesis

19 Véase especialmente Zaczyk (2008: 249 y ss.); latamente al respecto, y en la misma dirección, Solari (2008: 31 y ss.). 
contractualista, la justicia de la pena queda sometida a su compatibilidad con la exigencia de que el condenado haya consentido su eventual imposición y ejecución (Nino 1980: 225 y ss.). El argumento de Beccaria se apoya, entonces, en la proposición de que no es posible reconocer semejante consentimiento respecto de la imposición futura de la pena de muerte. Puesto que el argumento descansa en una base contrafáctica, consistente en la (supuesta) imposibilidad de imaginar tal consentimiento efectivo en la futura sujeción de sí mismo a una condena a muerte, cabe hablar a este respecto de un principio del consentimiento presunto.

Es justamente contra la invocación del principio del consentimiento en la pena que se dirige la embestida de Kant, en cuya refutación del argumento de Beccaria aparece con particular claridad el rigorismo que usualmente se le atribuye. Kant no sólo parte atribuyendo a Beccaria la "sensiblería de una humanidad afectada, carente de imparcialidad", sino que califica el argumento en su conjunto como nada más que "sofismo y torcimiento del derecho" (Kant 1798: A 202, B 232). Más allá de su generosidad con los calificativos, Kant impugna la base misma del principio del consentimiento en la pena, al observar que "alguien sufre la pena no porque la haya querido, sino porque ha querido la acción punible" (Kant 1798: A 202, B 232).

Esta proposición se ve complementada por la consideración, introducida inmediatamente a continuación, de que la noción de querer el propio castigo constituye una contradictio in adjecto. Ello descansa en la hipótesis de que, en congruencia con la estricta distinción entre las esferas de la legalidad y la moralidad (Kant 1798: AB 15-18), ${ }^{20}$ la responsabilidad jurídico-penal es una responsabilidad que se atribuye heterónomamente, de lo cual cabe inferir una exigencia inmanente de alteridad subjetiva entre aquel que impone y aquel sobre quien se impone la pena correspondiente, sobre la base de tal atribución de responsabilidad. Así, toda relación jurídicamente punitiva tendría el carácter de una relación irreflexiva: $X$ no puede punir a X. ${ }^{21}$ En palabras de Kant: "Como co-legislador que dicta la ley penal, yo no puedo ser en absoluto la misma persona que, como súbdito, es penada con arreglo a la ley", pues "como tal, es decir, como criminal, es imposible que yo tenga una voz en la legislación", en razón de que "el legislador es sagrado" (Kant 1798: A 202-203, B 232). ${ }^{22}$

Esto último explica, por lo demás, que, tras caracterizar el derecho (subjetivo) de castigar como "el derecho del titular del mando [Befehlshaber] contra el subordinado de gravarlo con una aflicción en virtud de su crimen", Kant observe que quien ocupa la posición de supremacía en el Estado no puede

20 Al respecto, véase Solari (2008: 26 y ss.), a propósito de los pasos que condicionan la derivación del así llamado "principio del derecho" (Rechtsprinzip) a partir del imperativo categórico.

21 Véase sin embargo Zaibert (2006: 40 y s.), quien defiende una concepción del castigo que pretende ser compatible con la posibilidad conceptual de la punición de uno mismo. Pero Zaibert excluye de su definición todo componente que aluda a alguna posición institucional de autoridad de quien se desempeña como agente del castigo, que es lo decisivo para la tesis kantiana discutida en el texto principal. 
ser castigado, "sino que uno sólo puede sustraerse de su dominación" (Kant 1798: A 195, B 225). Ello es consistente con su posterior advertencia acerca de la imposibilidad de concebir una guerra entre Estados independientes como una "guerra punitiva" (Strafkrieg), "pues una pena sólo puede tener lugar en la relación de un superior (imperantis) frente al sometido (subditum)" (Kant 1798: A 221-222, B 252).

Kant ciertamente advierte la dificultad que ello trae consigo, si se tiene a la vista la exigencia de que la justificación de la punición muestre deferencia por la valoración de la autonomía personal que se sigue de la adopción del principio del respeto. Pero la salida al dilema tiene que ser encontrada, piensa Kant, a través de una disociación de la identidad particular de la persona que es condenada en cuanto homo phaenomenon, por una parte, frente a la participación puramente abstracta en la racionalidad jurídica de la legislación que le es propia en cuanto homo noumenon, por otra (Kant 1798: A 203, B 232-233). ${ }^{23}$ Una reformulación de esta disociación, aun cuando desacoplada de los presupuestos del criticismo trascendental, aparece en la distinción, actualmente asumida por los partidarios de una fundamentación ético-discursiva de la culpabilidad jurídico-penal, entre el rol de persona-de-derecho que exhibe un agente que, en el ejercicio de su autonomía privada, puede fungir como destinatario de un reproche punitivamente materializado, por un lado, y el rol político de ciudadano de una democracia que, exhibido por ese mismo agente en el ejercicio de su autonomía pública, lo constituye en coautor de la norma legislativamente producida cuyo quebrantamiento puede resultar jurídicamente reprochable, por otro (Günther 2005: 245 y ss.; Mañalich 2007: 183 y ss.).

Es precisamente una confusión - por vía de identificación- de ambas posiciones, mutuamente excluyentes en un mismo contexto de fundamentación, lo que Kant imputa a Beccaria. El "punto neurálgico del error sofista" en que este incurriría consiste en la pretendida redefinición del (potencial) juicio evaluativo del propio criminal acerca de su merecimiento (adquirido) de una determinada sanción penal, como consecuencia del crimen que ha perpetrado, como una conclusión de su propia voluntad, en la forma de una manifestación de consentimiento, en cuanto a imponerse esa sanción a sí mismo, como si el propio criminal pudiera aparecer ocupando la posición del tribunal habilitado para ello (Kant 1798: A 203, B 232-233).

\section{LA NEUTRALIZACIÓN RETRIBUTIVA DE LA DISUASIÓN}

Hasta aquí se ha intentado delinear una lectura de algunos pasajes de aquella sección de la Rechtslehre en la que Kant ofrece una concepción general de la pena jurídica, que pretende dar cuenta del compromiso ilustradamente retribucionista de esa misma concepción, en cuanto fundada en una 
implementación multidimensional del principio del respeto. La defensa de esta lectura necesita desvirtuar, con todo, la persuasiva propuesta de exégesis elaborada por Byrd y Hruschka, ya referida, según quienes Kant atribuiría a la legislación penal una finalidad de prevención general de intimidación, en los términos de la teoría de la coacción psicológica posteriormente formulada por Feuerbach (Feuerbach 1832: §§ 12-18), mientras su defensa del así llamado "principio de la retribución" tendría el sentido de convertir a este en el estándar de fundamentación y determinación de la pena susceptible de ser judicialmente impuesta (Byrd y Hruschka: 2010: 261 y ss.). Pues de ser correcta esta lectura, y según ya se anticipara, Kant tendría que quedar incluido en el grupo de los partidarios de una teoría mixta o combinatoria de la justificación de la pena.

En lo fundamental, la propuesta de exégesis ofrecida por Byrd y Hruschka se apoya en dos argumentos disímiles, a saber: por una parte, en un argumento concerniente a "la función del derecho penal en un Estado de Derecho", que Kant habría identificado, exclusivamente, con "la protección de los derechos de los ciudadanos" (Byrd y Hruschka 2010: 264 y ss.); por otra parte, en un argumento de texto, referido al célebre pasaje en que Kant rechaza la existencia de un "derecho de necesidad" - y a la vez sienta las bases para el posterior desarrollo de la categoría de un estado de necesidad exculpante - a propósito del caso de la tabla de Carnéades (Hruschka 1991: 1 y ss.), ${ }^{24}$ en el cual Kant asumiría que la legislación penal persigue la obtención de un efecto —en la terminología de la teoría de los actos de habla: perlocutivo- de intimidación general (Byrd 1989: 189 y ss.; Byrd y Hruschka 2010: 274 y s.; Blöser 2014: 169 y s.).

El primero de los dos argumentos es ineficaz para sustentar la conclusión a la que Byrd y Hruschka pretenden arribar. Pues es claro que la comprensión del derecho penal como "derecho de protección" es compatible con la renuncia a predicar una finalidad de prevención intimidatoria de las normas de sanción penal. Lo distintivo de una concepción retribucionista, a este respecto, está constituido por la adopción de un esquema normológicamente dualista de legitimación: en cuanto normas secundarias, las normas de sanción penal no protegen directamente los "derechos de los ciudadanos", sino que refuerzan la vigencia de normas primarias que a su vez dispensan protección a aquellos (Mañalich 2012: 580 y ss.). En tal medida, la punición retributiva ajustada a la respectiva norma de sanción penal contribuye al reforzamiento de la autoridad normativa del Estado, en circunstancias de que son las normas primarias de comportamiento autoritativamente validadas por el Estado las que se orientan a la protección de los derechos de los ciudadanos.

El segundo argumento, empero, parece difícil de contrarrestar. Pues en efecto dice Kant, en referencia a la situación en la cual se encuentra aquel náufrago que salva su propia a costa de la vida del otro:

24 Acerca de la genealogía de la consideración filosófica y doctrinal del caso, véase Mañalich (2013b: 276 y ss.), con referencias ulteriores. 
No puede haber ley penal alguna que prevea la muerte para aquel que, flotando con otro en idéntico peligro para su vida con ocasión de un naufragio, aparta a este de un empujón desde la tabla sobre la cual se ha salvado, para así salvarse a sí mismo. Pues la pena amenazada a través de la ley no podría ser mayor que la pérdida de la vida del primero. Por lo demás, semejante ley penal no puede tener el efecto pretendido; pues la amenaza con un mal que todavía es incierto (a saber, la muerte por sentencia judicial) no puede superar el temor ante el mal que es cierto (a saber, el ahogarse) [Kant 1798: AB 41-42].

El pasaje ofrece inequívoco respaldo textual a la tesis según la cual Kant habría reconocido una finalidad de prevención general negativa a la legislación penal como tal. En contra de lo sugerido por Byrd y Hruschka, sin embargo, ello no refuta, sino que más bien confirma — cabría decir: irónicamente- la caracterización de la concepción kantiana de la justificación de la punición jurídica como una concepción propiamente retribucionista.

Para comprobar lo anterior, cabe reparar en que Kant esgrime dos consideraciones sucesivas que dejan entrever su propia representación de los presupuestos factuales de la realización de la finalidad de intimidación general atribuible a la legislación penal, en cuanto presupuestos fallidos en un caso como el de la tabla de Carnéades. Por un lado, Kant parece sugerir que, en pos de que la conminación legislativa de la pena en cuestión pueda producir un efecto disuasivo, sería necesario que el mal amenazado como pena supere el beneficio que el agente pudiera conseguir a través de su comportamiento delictivo. En el caso de la tabla de Carnéades, ese presupuesto falla, puesto que el mal consistente en la destrucción de la vida del condenado, a través de la ejecución de una pena de muerte como consecuencia jurídica del homicidio perpetrado sobre el otro náufrago, es sin más equivalente al mal cuyo padecimiento es impedido (en su propio interés) por el primer náufrago a través de la ejecución de la maniobra de autosalvamento a la vez productiva de la muerte del segundo. Y por otro lado, Kant observa que, en este mismo caso, la —irreductible - incertidumbre acerca de la contingencia de la imposición y ejecución de la pena (de muerte) conspiraría contra la eficacia disuasiva de su previa conminación legislativa, en razón de la cabal certeza que ese agente tendría del acaecimiento de su propia muerte, en caso de que él se abstuviera de salvarse a costa de la vida del otro náufrago.

Notablemente, las consideraciones de Kant reproducen con exactitud la identificación más recurrente de dos factores cuya multiplicación arrojaría el índice de eficacia disuasoria que pudiera esperarse de la conminación legislativa de una sanción, a saber: la magnitud de la sanción cuya imposición se anuncia, por un lado, y la probabilidad de que ella llegue a ser impuesta y ejecutada, 
por otro. ${ }^{25}$ Más allá de lo altamente inverosímil que resulta la hipótesis de la satisfacción del conjunto de precondiciones de las cuales dependería que el anuncio legislativo de sanciones pudiera desplegar un efecto disuasivo empíricamente verificable (Robinson 2008: 58 y ss.), ${ }^{26}$ es crucial advertir que la caracterización que Kant ofrece del canon de aplicación judicial de la legislación penal en efecto neutraliza, íntegramente, cualquier finalidad de intimidación general que pudiera atribuírsele (Hill 1997: 309 y ss.).

Esta neutralización queda determinada por la caracterización de la ley penal como un imperativo categórico: la pena legalmente prevista ha de ser judicialmente impuesta sobre el criminal "por el solo hecho de que él ha perpetrado el crimen", sin que ello pueda verse impactado por consideraciones prudenciales concernientes a la manera en la cual su imposición pudiera fungir como "un medio para promover algún otro bien, ya sea para el criminal mismo, ya sea para la sociedad civil" (Kant 1798: A 196, B 226). ${ }^{27}$ Notablemente, Hruschka enfatiza que en este punto radicaría la divergencia fundamental entre las concepciones de la legitimación de la punición estatal propuestas por Kant y por Feuerbach: mientras para este último la finalidad — aun cuando no el fundamento- de la imposición (y ejecución) de la pena consiste en hacer eficaz la previa amenaza legislativa, por la vía de demostrar su seriedad, Kant no legitima la imposición judicial de la pena legalmente conminada en referencia a finalidad alguna (Hruschka 2011: 34). Pues esa acción judicial ha de constituir la conclusión de un silogismo cuya premisa mayor estaría constituida por la respectiva norma de sanción en cuanto estándar categórico de adjudicación (Hruschka 2011: 29). Con ello, la caracterización kantiana de la posición institucional del adjudicador habilitado para la aplicación de la respectiva norma de sanción se traduce en la postulación de una estricta "desconexión teleológica" entre el anuncio legislativo y la eventual imposición judicial de la pena.

Esto contribuye a clarificar la manera en que la caracterización kantiana de la posición institucional del tribunal competente para la aplicación de la respectiva norma de sanción penal resulta incompatible con un diseño legislativo de la praxis de la punición estatal que pudiese ser globalmente legitimada por la persecución de una finalidad de intimidación general. Aquí es determinante volver sobre la observación de Kant en cuanto a que, en el caso de la tabla de Carnéades, en la situación en la que se encuentra el náufrago que salva su propia vida a costa de la vida del otro falla, desde ya, el presupuesto de eficacia disuasiva de la conminación legal de la pena consistente en que el mal amenazado sea superior al beneficio que el destinatario situacional de esa amenaza podría

25 Véase en detalle Robinson (2008: 32 y ss.), quien da cuenta de la necesidad de añadir la variable de la mayor o menor tardanza en la (eventual) imposición y ejecución de la sanción como ulterior factor a incorporar en el esquema de análisis.

26 Entre esas precondiciones destaca, desde ya, el presupuesto de un cabal conocimiento de la norma de sanción que especifica la pena cuya imposición y ejecución arriesga el potencial autor en caso de llegar a ser efectivamente perseguido; para la crítica de la teoría feuerbachiana de la coacción psicológica en este punto, véase Beling (1908: 82 y s.).

$27 \quad$ Al respecto Hruschka (2011: 28 y ss.). 
obtener al perpetrar el hecho en cuestión. Y el punto es que este presupuesto no puede sino fallar sistemáticamente si la pena anunciada por la ley ha de ser una proporcional al crimen en cuya virtud esa pena puede ser judicialmente impuesta, desde ya si — como Kant lo exige — tal relación de proporcionalidad queda determinada por el "derecho a la retribución", identificado con el ius talionis. $^{28}$

Con ello, y dentro de los límites que se siguen de la subordinación de la punición al principio del respeto, la pena judicialmente impuesta sobre el criminal ha de ser estrictamente proporcional a ese mismo crimen. A este respecto, la principal contribución de la propuesta exegética ofrecida por Byrd y Hruschka radica precisamente en el hallazgo de que, con toda justicia, Kant puede ser considerado el precursor inmediato de la formulación del principio de legalidad por parte de Feuerbach (Byrd y Hruschka 2010: 270 y ss.; Hruschka 2011: 18 y ss., 28 y ss.). Pero esto significa, entonces, que la pena susceptible de ser impuesta sobre el criminal tiene que ser la pena legalmente prevista para el crimen que se le imputa. ¿Pero de qué depende que la pena proporcionalmente adecuada al crimen en cuestión, que es la única pena cuya imposición judicial resulta retributivamente legítima, sea la pena ya previamente prevista por la respectiva ley penal para un crimen de ese mismo tipo? La respuesta es clara: ello depende de que la pena legalmente conminada sea ya una proporcionalmente adecuada, esto es, una pena equivalente en su severidad a la gravedad del crimen que esa misma ley especifica.

En tal medida, el sometimiento simultáneo de la adjudicación jurídicopenal tanto al principio formal de legalidad como al principio retributivo de proporcionalidad, reclamado por Kant, sólo parece posible a través de la renuncia a una formulación legislativa de la respectiva norma de sanción que pudiera resultar idónea para la realización de una finalidad de intimidación general.

\section{ASTUCIA PUNITIVA VERSUS JUSTICIA PUNITIVA}

En la desconexión teleológica a la que Kant somete la punición se hace patente su cabal asunción de una muy importante distinción que él mismo introduce en una nota al pie de página complementaria de un anexo a la sección dedicada al

28 En esto consiste, precisamente, lo que Goldman (1979: 47 y ss.) llamó "la paradoja del castigo", a saber: el dilema que inevitablemente enfrentaría toda teoría mixta que pretende hacer compatible la obtención de una finalidad de disuasión general a través de la conminación y la imposición de penas, por un lado, con el constreñimiento representado por el principio retributivo de equivalencia entre crimen y pena, por otro. El esfuerzo de Blöser (2014: 176 y ss.) por defender la caracterización de la concepción kantiana de la pena jurídica como una variante de semejante teoría mixta, y que descansa en la hipótesis de que la observancia de la exigencia de proporcionalidad no necesitaría comprometer la eficacia disuasiva de la punición, en la medida en que el efecto intimidatorio de esta habría de ser añadido a "las sanciones morales internas" susceptibles de verse activadas en el destinatario de la amenaza punitiva en cuanto "sujeto moral autónomo", se ve severamente comprometido por la muy discutible verosimilitud empírica de este último presupuesto. 
"derecho de castigar". Se trata de la distinción entre dos argumentos susceptibles de ser esgrimidos para la fundamentación de la punición, a saber: un argumento de "astucia punitiva" (Strafklugheit), según el cual se castiga para que no se delinca (punitur ne peccetur), y otro de "justicia punitiva" (Strafgerechtigkeit), según el cual se castiga porque se ha delinquido (punitur quia peccatum est) [Kant 1798: B 170-171]..$^{29}$

El primero es caracterizado como un argumento "meramente pragmático", en tanto que el segundo como uno "moral". Esto se traduce en que, en la tópica de los conceptos jurídicos, uno y otro argumento ocupen lugares diferentes. Como lo mostrara Hruschka, la caracterización del argumento de justicia punitiva como uno "moral" no implica que este pertenezca a la esfera de la moralidad, en contraposición a la esfera de la legalidad. Pues en el sentido aquí relevante, lo moral se entiende en oposición a lo físico, de modo tal que, en jerga kantiana, el derecho y la ética integran por igual el campo de lo moral (Enderlein 1985: 305 y s.; Blöser 2014: 11 y s.; Willaschek 2017: 98 y ss.). Y puesto que el lugar de una "metafísica de las costumbres" al que corresponde la pregunta por la justicia de la pena jurídica es la Rechtslehre, y no la Sittenlehre, es claro que Kant entiende el argumento "moral" de la justicia punitiva como un argumento jurídico (Hruschka 2011: 25).

Al contraponer los argumentos de justicia punitiva a los argumentos de astucia punitiva, Kant mostraba una muy lúcida convicción en el rendimiento que una concepción filosófica de la pena jurídica orientada a la retribución puede tener en la impugnación crítica de la —a veces demasiado — astuta política criminal.

\section{REFERENCIAS}

Aichele, Alexander. 2008. "Persona physica und persona moralis: Die Zurechnungsfähigkeit juristischer Personen nach Kant." Jahrbuch für Recht und Ethik 16: 3-23.

Allison, Henry. 2011. Kant's Groundwork for the Metaphysics of Morals. Oxford; New York York: Oxford University Press.

Beccaria, Cesare. [1764] 1968. De los delitos y las penas. Madrid: Alianza.

Beling, Ernst. 1908. Die Vergeltungsidee und ihre Bedeutung für das Strafrecht. Leipzig: Wilhelm Engelmann.

Birnbacher, Dieter. 2007. Analytische Einführung in die Ethik. $2^{\mathrm{a}}$ ed. Berlin; New York: Walter de Gruyter.

Blöser, Claudia. 2014. Zurechnung bei Kant. Berlin; Boston: De Gruyter.

Byrd, Sharon. 1989. "Kant's Theory of Punishment: Deterrence in its Threat, Retribution in its Execution." Law and Philosophy 8 (2): 151-200.

Byrd, Sharon y Joachim Hruschka. 2010. Kant's Doctrine of Right. Cambridge; New York: Cambridge University Press.

Corlett, J. Angelo. 2013. Responsibility and Punishment. $4^{\mathrm{a}}$ ed. Dordrecht: Springer.

Donoso, Alfonso. 2014. "Traditional Retributivism." En Encyclopedia of Criminology and Criminal Justice, editado por Gerben Bruinsma y David Weisburd. New York: Springer, 5239-5249. 
Enderlein, Wolfgang. 1985. "Die Begründung der Strafe bei Kant", Kant-Studien 76: 303-327.

Falls, Margaret. 1987. "Retribution, Reciprocity, and Respect for Persons." Law and Philosophy 6 (1): 25-51.

Feuerbach, Paul Anselm von. 1832. Lehrbuch des gemeinen in Deutschland gültigen peinlichen Rechts. $11^{a}$ ed. Gießen: Georg Friedrich Heyer.

Goldman, Alan. 1979. “The Paradox of Punishment." Philosophy \& Public Affairs 9 (1): 42-58.

Günther, Klaus. 2005. Schuld und kommunikative Freiheit. Frankfurt am Main: Vittorio Klostermann.

Hegel, G.W.F. [1821] 1911. Grundlinien der Philosophie des Rechts. Leipzig: Felix Meiner.

Hill, Thomas. 1997. "Kant on Punishment: A Coherent Mix of Deterrence and Retribution?" Jahrbuch für Recht und Ethik 5: 291-314.

Hoerster, Norbert. 2012. Muss Strafe sein? München: C.H. Beck.

Hruschka, Joachim. 1991. "Rechtfertigungs- und Entschuldigungsgründe: Das Brett des Karneades bei Gentz und Kant." Goltdammer's Archiv für Strafrecht 138: 1-10.

Hruschka, Joachim. 2010. “Die ,Verabschiedung' Kants durch Ulrich Klug im Jahre 1968: Einige Korrekturen." Zeitschrift für die gesamte Strafrechtswissenschaft 122: 493-503.

Hruschka, Joachim. 2011. "Kant, Feuerbach und die Grundlagen des Strafrechts." En Strafrechtswissenschaft als Analyse und Konstruktion. Festschrift für Ingeborg Puppe zum 70. Geburtstag, coordinado por Urs Kindhäuser, Ulfrid Neumann y Hans-Ullrich Paeffgen. Berlin: Duncker \& Humblot, 17-37.

Kant, Immanuel. [1788] 1974. Kritik der praktischen Vernunft, Werksausgabe VII. Frankfurt am Main: Suhrkamp.

Kant, Immanuel. [1798] 1977. Die Metaphysik der Sitten. 2a ed. Werksausgabe VIII. Frankfurt am Main: Suhrkamp.

Klug, Ulrich. 1981. Skeptische Rechtsphilosophie und humanes Strafrecht, tomo II. Berlin; Heidelberg; New York: Springer.

Mañalich, Juan Pablo. 2007. "La pena como retribución." Estudios Públicos 108: 117-205.

Mañalich, Juan Pablo. 2011. "Beccaria: la pena como exclusión." En Pena y culpabilidad en el Estado democrático de derecho, $2^{a}$ ed., de Urs Kindhäuser y Juan Pablo Mañalich. Montevideo; Buenos Aires: BdF, 251-287.

Mañalich, Juan Pablo. 2012. "Reglas primarias de obligación. Las 'reglas del derecho penal' en El Concepto de Derecho de H.L.A. Hart." Zeitschrift für Internationale Strafrechtsdogmatik 11: 571-585. Recuperado el 17 de agosto de 2017 de http:/ / zis-online.com/dat/ artikel/2012_11_716.pdf.

Mañalich, Juan Pablo. 2013a. "Justicia, propiedad y prevención." En La ciencia penal en la Universidad de Chile, coordinado por Juan Pablo Mañalich. Santiago: Facultad de Derecho, Universidad de Chile, 167-187.

Mañalich, Juan Pablo. 2013b. “Normas permisivas y deberes de tolerancia." En La antijuridicidad en el Derecho penal, coordinado por Juan Pablo Mañalich. Montevideo; Buenos Aires: BdF, 177-283.

Mañalich, Juan Pablo. 2015. "Retribucionismo consecuencialista como programa de ideología punitiva." InDret 2. Recuperado el 17 de agosto de 2017 de http: / / www.indret.com/ pdf/1126.pdf.

Murphy, Jeffrie. 1970. Kant: The Philosophy of Right. London; Basingstoke: Macmillan.

Murphy, Jeffrie. 1979. Retribution, Justice, and Therapy. Dordrecht: Reidel.

Murphy, Jeffrie. 1987. "Does Kant Have a Theory of Punishment?" Columbia Law Review 87 (3): 509-532.

Neumann, Ulfrid y Ulrich Schroth. 1980. Neuere Theorien von Kriminalität und Strafe. Darmstadt: Wissenschaftliche Buchgesellschaft.

Nino, Carlos Santiago. 1980. Los límites de la responsabilidad penal. Buenos Aires: Astrea.

Nino, Carlos Santiago. 2008. Fundamentos de Derecho Penal. Buenos Aires: Gedisa.

Nozick, Robert. 1981. Philosophical Explanations. Cambridge: Harvard University Press.

Robinson, Paul. 2008. Distributive Principles of Criminal Law. Oxford; Nueva York: Oxford University Press. 
Sánchez-Ostiz, Pablo. 2008. Imputación y teoría del delito. Montevideo; Buenos Aires: BdF.

Solari, Enzo. 2008. "La pena de muerte según Kant." En Delito, pena y proceso. Libro homenaje a la memoria del profesor Tito Solari Peralta, coordinado por Luis Rodríguez Collao. Santiago: Editorial Jurídica de Chile, 21-40.

Stübinger, Stephan. 2011. "Von der alten Imputationen-Lehre zum klassischen Verbrechensbegriff - Ein Beitrag zur Geschichte des strafrechtlichen Zurechnungsbegriffs." Rechtswissenschaft 2: 154-76.

Timmermann, Jens. 2007. Kant's Groundwork of the Metaphysics of Morals. Cambridge: Cambridge University Press.

Tugendhat, Ernst. 1993. Vorlesungen über Ethik. Frankfurt am Main: Suhrkamp.

Vilajosana, Josep. 2015. Las razones de la pena. Valencia: Tirant lo Blanch.

Willaschek, Marcus. 2017. "Derecho y coacción. ¿Puede derivarse la concepción del derecho de Kant de su teoría moral?" En Forzados a ser libres. Kant y la teoría republicana del derecho, editado por Juan Ormeño y Miguel Vatter. Santiago: Fondo de Cultura de Económica, 97-128.

Wittgenstein, Ludwig. [1958] 2009. Philosophische Untersuchungen, $4^{\mathrm{a}}$ ed. Oxford: Wiley-Blackwell.

Wood, Allen. 2008. Kantian Ethics. Cambridge: Cambridge University Press.

Wood, Allen. 2010. "Punishment, Retribution, and the Coercive Enforcement of Right." En Kant's Metaphysics of Morals, editado por Lara Denis. Cambridge: Cambridge University Press, 111-129.

Zaczyk, Rainer. 1999. "Staat und Strafe - Bemerkungen zum sogenannten ,Inselbeispiel' in Kants Metaphysik der Sitten." En Freiheit, Gleichheit, Selbstständigkeit, coordinado por Götz Landwehr. Hamburg: Joachim Jungius-Gesellschaft, 73-87.

Zaczyk, Rainer. 2008. ",Hat er aber gemordet, so muß er sterben'. Kant und das Strafrecht." En Kant-Lektionen. Zur Philosophie Kants und zu Aspekten ihrer Wirkungsgeschichte, coordinado por Manfred Kugelstadt. Wurzburgo: Königshausen \& Neumann, 241-257.

Zaibert, Leo. 2006. Punishment and Retribution. Aldershot: Ashgate.

Recibido: 11.09.2017

Aceptado: 08.02.2018

Juan Pablo Mañalich es Profesor titular del Departamento de Ciencias Penales, doctor en derecho por la Universidad de Bonn (2008) y licenciado en Ciencias Jurídicas y Sociales por la Universidad de Chile (2004). Desde septiembre de 2017, es Director del Departamento de Ciencias Penales. Ha sido becario doctoral del Servicio Alemán de Intercambio Académico (DAAD) y becario posdoctoral de la Fundación Alexander von Humboldt. Es autor de las monografías Nötigung und Verantwortung (2009), Autotutela del acreedor y protección penal del deudor (2009), Terror, Pena y Amnistía (2010), Pena y culpabilidad en el Estado democrático de derecho, en conjunto con Urs Kindhäuser (2011), Norma, causalidad y acción (2014), y Estudios sobre la fundamentación y la determinación de la pena (2018). Email: jpmanalich@derecho.uchile.cl 